\title{
Growth of AIN oriented films on insulating substrates
}

\author{
J. Olivares, J. Capilla, M. Clement, J. Sangrador, and E. Iborra \\ Grupo de Microsistemas y Materiales Electrónicos (GMME.-CEMDATIC). Universidad Politécnica de Madrid \\ Madrid, Spain \\ olivares $a$ etsit.upm.es
}

\begin{abstract}
This work describes the structural and piezoelectric assessment of aluminum nitride (AIN) thin films deposited by pulsed-DC reactive sputtering on insulating substrates. We investigate the effect of different insulating seed layers on AIN properties (crystallinity, residual stress and piezoelectric activity). The seed layers investigated, silicon nitride $\left(\mathrm{Si}_{3} \mathbf{N}_{4}\right)$, silicon dioxide $\left(\mathrm{SiO}_{2}\right)$, amorphous tantalum oxide $\left(\mathrm{Ta}_{2} \mathrm{O}_{5}\right)$, and amorphous or nano-crystalline titanium oxide $\left(\mathrm{TiO}_{2}\right)$ are deposited on glass plates to a thickness lower than $100 \mathrm{~nm}$. Before AIN films deposition, their surface is pre-treated with a soft ionic cleaning, either with argon or nitrogen ions. Only AIN films grown of $\mathrm{TiO}_{2}$ seed layers exhibit a significant piezoelectric activity to be used in acoustic device applications. Pure c-axis oriented films, with FWHM of rocking curve of $6^{\circ}$, stress below $500 \mathrm{MPa}$, and electromechanical coupling factors measured in SAW devices of $1.25 \%$ are obtained. The best AIN films are achieved on amorphous $\mathrm{TiO}_{2}$ seed layers deposited at high target power and low sputtering pressure. On the other hand, AlN films deposited on $\mathrm{Si}_{3} \mathrm{~N}_{4}, \mathrm{SiO}_{2}$ and $\mathrm{TaO}_{x}$ exhibit a mixed orientation, high stress and very low piezoelectric activity, which invalidate their use in acoustic devices.
\end{abstract}

\section{INTRODUCTION}

The growth of AlN thin films with good crystal quality and piezoelectric activity on insulating thin films is still a pending matter, as the oriented growth of AlN requires specific surface conditions, which are mainly achieved in metallic layers ( $\mathrm{Ir}, \mathrm{Ru}, \mathrm{Pt}, \mathrm{W}$ or $\mathrm{Mo}$ ) [1], or single crystal insulating substrates, such as sapphire, quartz or lithium niobate [2]. However, these layered structures are required in many applications, such as surface acoustic wave (SAW) devices [2], laterally excited shear mode resonators [3] or bulk acoustic wave (BAW) composite resonators with insulating layers for temperature compensation [4]. AlN films are frequently grown over silicon dioxide $\left(\mathrm{SiO}_{2}\right)$ thin films; actually, AlN films with significant piezoelectric activity deposited on $\mathrm{SiO}_{2}$ substrates have been reported recently [5]. To achieve highly c-axis oriented AlN films in $\mathrm{SiO}_{2}$ substrates, the deposition process has to be tuned carefully, which generally requires a considerable increase of the voltage bias applied to the substrates. This causes a severe increase of the compressive residual stress of the AlN films, as we reported in our previous investigations on RF-sputtered AlN films on $\mathrm{SiO}_{2}$ [6]. Moreover, AlN deposition is critically dependent on the deposition system, as the energetic bombardment of the film during growth depends on the chamber geometry and on the electric and magnetic fields arrangement [7]. In order to reduce the stress built on the films undergoing a severe energetic bombardment, we have investigated the effect of using a thin insulating interlayer that would act as a seed layer for the growth of c-axis oriented AlN films. This would allow to reduce the energy feed to the substrate required to achieve well oriented films. We have investigated the growth of AIN on silicon nitride $\left(\mathrm{Si}_{3} \mathrm{~N}_{4}\right)$, tantalum oxide $\left(\mathrm{Ta}_{2} \mathrm{O}_{5}\right)$, sputtered $\mathrm{SiO}_{2}$ and $\mathrm{TiO}_{2}$. The sputtering process of $\mathrm{Si}_{3} \mathrm{~N}_{4}, \mathrm{Ta}_{2} \mathrm{O}_{5}$ and $\mathrm{SiO}_{2}$ had been already studied in previous works by the authors [8-9]. Since the best preliminary results were achieved when using $\mathrm{TiO}_{2}$ seed layers, the present work is mainly focused on the study of the $\mathrm{TiO}_{2}$ deposition process in order to set the optimum conditions for the growth of high quality AlN films.

$\mathrm{TiO}_{2}$ thin films are widely used in different field, such as optical-interference coatings [10], coatings for catalyst applications [11], and coatings for the biocompatibility of bone implants [12]. Titanium dioxide exists in both amorphous and crystalline form; this last comprises two crystalline polymorph phases, anatase and rutile, of tetragonal structure. The rutile phase more stable thermodynamically [13] but the more hard to obtain. There are many methods for the preparation of $\mathrm{TiO}_{2}$ films, such as chemical vapor deposition, ion beam-assisted deposition, reactive evaporation, sol-gel processes, and sputtering [14-18]. In particular, a magnetron sputtering technique seems to be the most favorable method. Most of the $\mathrm{TiO}_{2}$ films prepared by the above-mentioned methods are either amorphous or nanocrystalline (anatase) and have to be heated to high temperatures (around $600{ }^{\circ} \mathrm{C}$ and above) to achieve the rutile crystalline phase [19]. According to [19], $\mathrm{TiO}_{2}$ films deposited without substrate heating by dc-sputtering exhibit the anatase phase.

In summary, we explore the possibility of growing $c$-axis oriented AlN thin films by pulsed-dc sputtering on insulating glass substrates covered by different seed layers (specially $\mathrm{TiO}_{2}$ ), paying a special attention to the influence of their crystalline properties and to the preconditioning of their surface by in-situ ion bombardment just before AlN deposition. 


\section{EXPERIMENTAL}

\section{A. Sputtering Process}

The seed layers investigated $\left(\mathrm{Si}_{3} \mathrm{~N}_{4}, \mathrm{Ta}_{2} \mathrm{O}_{5}, \mathrm{SiO}_{2}\right.$, and $\mathrm{TiO}_{2}$ ) were deposited in a Leybold Z- 550 system by a pulsed$\mathrm{DC}$ reactive magnetron sputtering process. High-purity $\mathrm{Si}, \mathrm{Ta}$ and Ti targets $150 \mathrm{~mm}$-in-diameter were sputtered using $\mathrm{Ar} / \mathrm{O}_{2}$ mixtures of different composition. The deposition process of both $\mathrm{SiO}_{2}$ and $\mathrm{TaO}_{\mathrm{x}}$ films had been extensively studied previously; details of the film characteristics as a function of the sputter parameters can be found in earlier works $[8,9]$. The sputtering process of the $\mathrm{TiO}_{2}$ films was carried out by applying to the Ti target a pulsed-DC power of $50 \mathrm{kHz}$ and duty cycle of $75 \%$ ranging from $200 \mathrm{~W}$ to $800 \mathrm{~W}$. The total pressure in the chamber was varied between 1.5 mTorr and 3.3 mTorr and the percentage of $\mathrm{O}_{2}$ in the gas between $30 \%$ and $100 \%$. During the deposition process the substrates were not intentionally heated. In all cases, the thickness of the seed layer varied between $50 \mathrm{~nm}$ and $100 \mathrm{~nm}$.

The sputter process of the $\mathrm{Ti}$ target in $\mathrm{Ar} / \mathrm{O}_{2}$ atmospheres exhibited a transitory behavior, similar to that of any metallic target undergoing a reactive sputtering process at constant power under oxygen atmospheres, owing the oxidation of its surface. We experimentally checked that any $\mathrm{TiO}_{2}$ film deposited in the metallic regime exhibited a conductive behavior, regardless of the deposition conditions. Hence, all the samples investigated here were grown in the poisoned regime. For each pulsed DC power we determined first the minimum gas pressure necessary to switch on the discharge in the chamber. Then the gas ratio was adjusted until the target switched to the poisoned regime, which was controlled by monitoring the evolution of its voltage. Once the voltage stabilized, a first layer was deposited under these conditions (close to the metallic/poisoned transition). Then, the oxygen ratio was the increased considerably while keeping constant the total pressure, in order to grow a second layer in the deep poisoned regime (far from the transition)

The films were deposited on Corning glass plates 500 $\mu \mathrm{m}$-thick and on (100) silicon wafers for IR transmission and reflection measurements. Before AIN deposition the substrates were degassed close to the AlN deposition temperature (400 ${ }^{\circ} \mathrm{C}$ ). Then, the surface of the seed layers were soft etched by means of a short bombardment $(60 \mathrm{~s})$ with $\mathrm{Ar}^{+}$or $\mathrm{N}_{2}^{+}$ions from an RF glow discharge generated near the substrate. Once the surface prepared, the AlN films were sputtered on top of the seed layers using a 3:7 Ar: $\mathrm{N}_{2}$ admixture at a total pressure of 1.2 mTorr, a pulsed-DC power of $1.2 \mathrm{~kW}$ and a platen temperature of $400^{\circ} \mathrm{C}$. An RF bias of $-77 \mathrm{~V}$ was applied to the substrates to tune the stress in the AlN films. These conditions provided deposition rates of $40 \mathrm{~nm} \cdot \mathrm{min}^{-1}$. The thickness of the AlN film always was around $1 \mu \mathrm{m}$. We have experimentally checked that these deposition conditions provide AlN films of excellent crystal quality and piezoelectric response when deposited on metallic electrodes (Ir or Mo) [20].

In order to asses the piezoelectric activity of the AIN films, SAW delay lines were fabricated in the surface of the AIN films by defining interdigital transducers (IDTs) on a Mo film $100 \mathrm{~nm}$-thick. Each IDT had 40 pairs of bars separated $10 \mu \mathrm{m}$, corresponding thus to a wavelength of $40 \mu \mathrm{m}$. SAW delay lines were stuck to a test fixture and the pads of the IDTs ultrasonically bonded using $25 \mu \mathrm{m}$-wide aluminum wires of 5 to $10 \mathrm{~mm}$. The scattering parameters $S_{i j}$ of the SAW delay lines were measured between $100 \mathrm{kHz}$ and $700 \mathrm{MHz}$ with an Agilent network analyzer PNA N5230A. The experimental spectra were fitted using our own simulation program based on Campbell's method [21], which has been described in a previous work [22]. This model eliminate the effects of the impedance mismatch at the input and output ports due to the non-optimized geometry and to parasitic effects such as the series resistance, the wire inductance, the electromagnetic feedtrough between the IDTs and the effects of the inductance and the resistance in the ground loop. All these non desired effects distort the frequency response of a real delay line. After the fitting, we obtained the electromechanical coupling factor associated to the excitation of a Rayleigh wave in an ideal semi infinite AlN substrate, which we will call $\mathrm{k}_{\text {SAW; }}^{2}$; this factor is only dependent on the AlN material properties and independent of the geometry of the layered structure. This $\mathrm{k}_{\mathrm{SAW}}^{2}$ is used to compare the piezoelectric performance of the AlN film of the device. Fig. 1 shows the response of three SAW delay lines of AlN films deposited on $\mathrm{TiO}_{2}, \mathrm{SiO}_{2}$ and $\mathrm{Ta}_{2} \mathrm{O}_{5}$ seed layers., after de-embedding the parasitic effects.

X-ray diffraction patterns of the processed samples were measured in conventional Bragg-Brentano geometry in a Supratech XPert MRD diffractometer between $2 \theta=10^{\circ}$ and $2 \theta=80^{\circ}$. The in-plane residual stress of the AlN films was derived from the measurement of the curvature of the surface before and after the film deposition using the Stoney's formula.

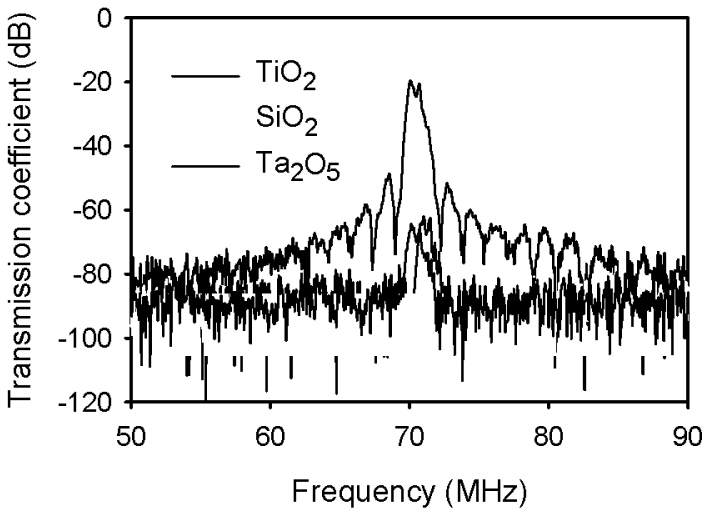

Figure 1. Transmissin coefficient of three $\mathrm{SAW}$ delay lines fabricated on AlN deposited on $\mathrm{TiO}_{2}, \mathrm{SiO}_{2}$ and $\mathrm{Ta}_{2} \mathrm{O}_{5}$ seed layers.

\section{RESULTS AND DISCUSSION}

AlN films did not adhere to $\mathrm{Si}_{3} \mathrm{~N}_{4}$ seed layers so these were discarded from the study. On the other hand, AlN films grown on $\mathrm{SiO}_{2}$ and $\mathrm{Ta}_{2} \mathrm{O}_{5}$ substrates under standard conditions exhibited a very poor crystallinity with mixed orientations $(00 \cdot 2,10 \cdot 3$ and $10 \cdot 2$ peaks $)$ and did not possess a significant piezoelectric response as shown in Fig. 1. This type of AlN films have been widely described in [23]. To achieve AlN films on $\mathrm{SiO}_{2}$ and $\mathrm{Ta}_{2} \mathrm{O}_{5}$ substrates with a significant piezoelectric activity a great negative polarization has to be applied to the substrate during deposition. This provides $00 \cdot 2$ 
oriented films with a homogenous polar orientation, as previously discussed in [6]. However, the high substrate bias induces a strong ionic bombardment on the surface of the AlN film during the deposition. As a consequence, the crystal quality dramatically drops and the residual stress increases to values higher than $2 \mathrm{GPa}$. This high stress induces the films of the layered structure to lift off from the glass substrate. Therefore, $\mathrm{SiO}_{2}$ and $\mathrm{Ta}_{2} \mathrm{O}_{5}$ along with $\mathrm{Si}_{3} \mathrm{~N}_{4}$ are not good candidates as seed layers for sputtered AlN films.

AIN films deposited on $\mathrm{TiO}_{2}$ in similar conditions than those grown on metallic substrates show a definite $00 \cdot 2$ orientation (although with wider rocking curves); additionally, the films possess low residual stress (300 MPa) and a piezoelectric activity good enough to justify their use in acoustic applications. We have found some trends in the variations of the AlN properties with the deposition conditions of the $\mathrm{TiO}_{2}$ seed layer. The most influent deposition conditions are the power applied to the target, the total pressure and the ionic pretreatment of the $\mathrm{TiO}_{2}$ seed layer, as will be shown in the following, were we compare the properties of AlN films grown on identical deposition conditions on differently deposited $\mathrm{TiO}_{2}$ seed layers. Fig. 2 shows the XRD patterns of some AlN films deposited on $\mathrm{TiO}_{2}$ substrates of different structure.

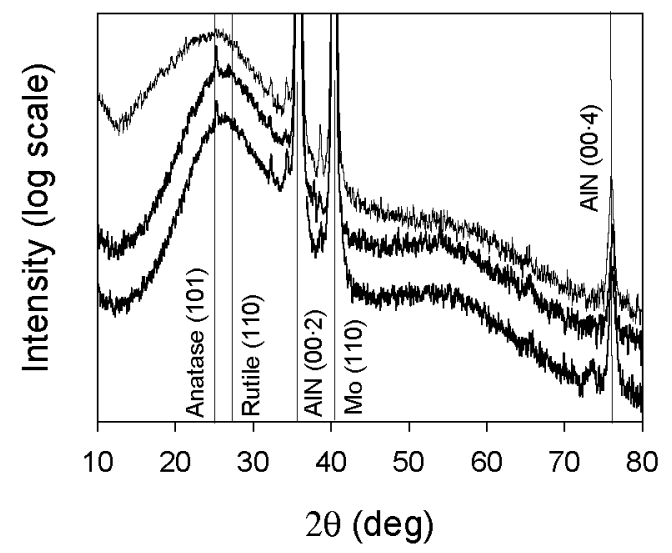

Figure 2. XRD patterns of $\mathrm{AlN} / \mathrm{TiO}_{2}$ films with different structures.

The most intense peaks correspond to the reflection in the $00 \cdot 2$-AIN and 111-Mo planes, these last coming for the metallic IDTs. In some samples other small peaks that appear in the XRD spectra can be associated to the anatase $(2 \theta=$ $25.6^{\circ}$ and $\left.38.2^{\circ}\right)$ and the rutile $\left(20=27.5^{\circ}\right)$ phases of $\mathrm{TiO} 2$. Their very low intensity suggests that the $\mathrm{TiO} 2$ films are essentially amorphous although some of them contain small amounts of embedded nano-crystals

Linking the piezoelectric response of the AlN films with the crystalline characteristics of the $\mathrm{TiO}_{2}$ seed layers is very difficult. Besides, relating the piezoelectric activity of the AlN films $\left(k_{\mathrm{SAW}}^{2}\right)$ with their crystalline characteristics brings surprising results, as the films with a larger piezoelectric activity $\left(k_{\mathrm{SAW}}^{2}-1.25 \%\right)$ exhibit very wide RCs (as high as $\left.16^{\circ}\right)$, whereas films of considerably narrower RCs $\left(\sim 6^{\circ}\right)$ have bad piezoelectric responses, as Fig. 3 shows.

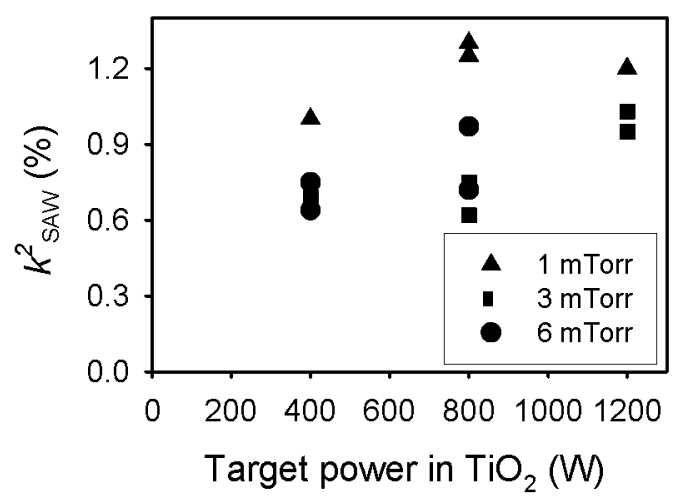

Figure 3. Values of $\mathrm{k}^{2}{ }_{\mathrm{SAW}}$ derived from test structures made on several AlN films deposited on $\mathrm{TiO}_{2}$ seed layers as a function of the FWHM of the RC of the $(00 \cdot 2)$ AlN direction.

If one keeps in mind that all the AlN films were deposited in the same run under identical condition, the observed behavior only has one explanation: the $\mathrm{TiO}_{2}$ surface conditions that stimulates the growth of highly oriented AIN and favors the narrowing of RCs is also responsible of the growth of AlN microcrystals with different polar orientations (inversion domains), that partially cancel the piezoelectric response of the films. Therefore, we have tried to find trends between the deposition conditions of $\mathrm{TiO}_{2}$ films and the piezoelectric activity of the subsequently grown AlN films, assessed through $k_{\mathrm{SAW}}^{2}$. Fig.4 shows the $k_{\mathrm{SAW}}^{2}$ of the devices as a function of the power applied to the Ti target during $\mathrm{TiO}_{2}$ deposition.

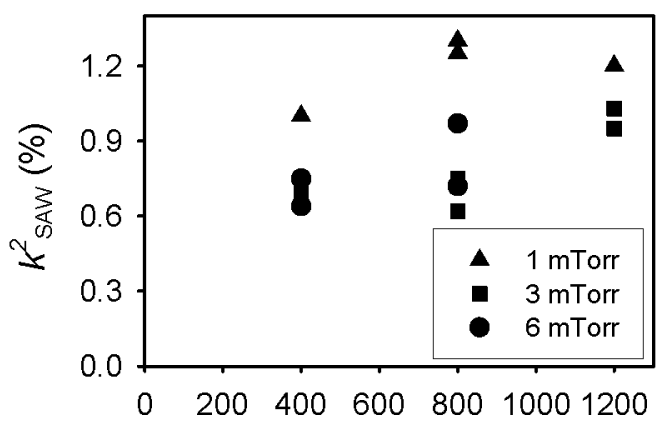

Target power in $\mathrm{TiO}_{2}(\mathrm{~W})$

Figure 4. Values of $\mathrm{k}_{\text {SAW }}^{2}$ as a function of the target power during $\mathrm{TiO}_{2}$ seed layer deposition.

According to the data of Fig.4, the piezoelectric activity of the AlN films apparently increase as the DC-pulsed power increases and when the pressure lowers. This indicates that a greater bombardment of the $\mathrm{TiO}_{2}$ film during its growth can help the growth of AIN films free of inversion domains. At high powers the plasma is denser, so there is a greater amount of ions and electrons in the discharge; furthermore, at low pressures the species impinge on the substrate with supplementary energy because they suffer less collisions with the gas of the discharge. Hence, under these conditions the energy delivered to the substrate is greater, which yields to $\mathrm{TiO}_{2}$ films with a homogeneous surface state that promotes the growth AlN films with uniform polar orientation. On the other hand, the ionic bombardment undergone by the $\mathrm{TiO}_{2}$ 
layers during growth may cause some disorder in the atomic arrangement of the $\mathrm{TiO}_{2}$ surface, which would be responsible of the widening of the RCs of the AIN films. This same mechanisms causes apparently a reduction of the residual stress, as can be seen in Fig. 5

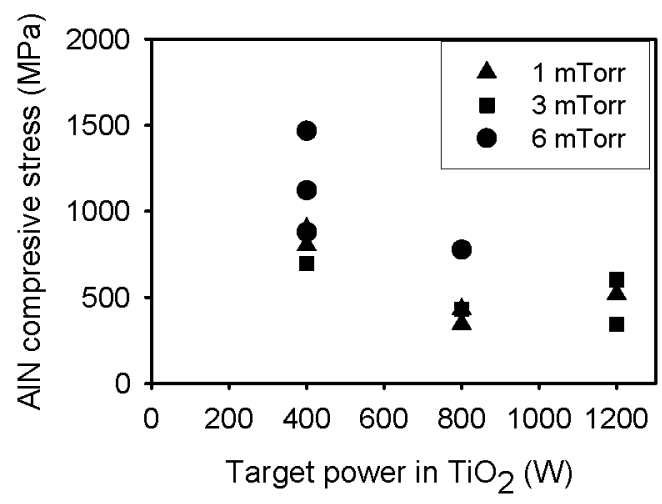

Figure 5. Values of residual stress as a function of the target power during $\mathrm{TiO}_{2}$ seed layer deposition.

\section{CONClusions}

AlN films $1 \mu \mathrm{m}$-thick were deposited on glass substrates covered by insulating seed layers of $\mathrm{Si}_{3} \mathrm{~N}_{4}, \mathrm{SiO}_{2}, \mathrm{Ta}_{2} \mathrm{O}_{5}$ and $\mathrm{TiO}_{2}$. The characteristics of the AlN films (stress, crystal structure and piezoelectric behavior) depended on the nature and structure of the seed layer. AlN films grown on $\mathrm{Si}_{3} \mathrm{~N}_{4}$ had low adherence and tended to peel off. Similarly, AlN deposited on $\mathrm{SiO}_{2}$ and $\mathrm{Ta}_{2} \mathrm{O}_{5}$ exhibited a residual stress that was not suitable for device fabrication. $\mathrm{TiO}_{2}$ seed layers promoted the growth of AIN films with residual stress below $500 \mathrm{MPa}$, purely $(00 \cdot 2)$-oriented, and $\mathrm{k}_{\mathrm{SAW}}^{2}$ of up to $1.25 \%$. The piezoelectric activity is not related to the width of the $\mathrm{RC}$ around the 00.2 peak. This behavior suggests that the mechanism stimulating the growth of purely oriented $(00 \cdot 2)$ films with narrow rocking-curve is also responsible of the growth of microcrystals with different polar orientations, which partially cancels the piezoelectric response of the films.

\section{ACKNOWLEDGMENT}

This work has been supported by the Ministerio de Ciencia e Innovación of Spain through project MAT2010-18933, and by the Comunidad de Madrid and the UPM through the IV PRICIT programme.

\section{REFERENCES}

[1] S. Inoue, K. Okamoto, T. Nakano, H. Fujioka, "Characteristics of single crystalline AlN films grown on Ru( $\left.\begin{array}{llll}0 & 0 & 0 & 1\end{array}\right)$ substrates", Journal of Crystal Growth 297 (2006) pp. 317-320.

[2] M. B. Assouar, O. Elmazria, P. Kirsch, P. Alnot, V. Mortet, and C. Tiusan, "High-frequency surface acoustic wave devices based on AIN/diamond layered structure realized using e-beam lithography", J. Appl. Phys. 101, 114507 (2007).

[3] Da Chen, J. Wang, D Li, Y. Xu, and Z. Li, "Solidly mounted resonators operated in thickness shear mode based on c-axis oriented AlN films," Sensors and Actuators A 165 (2011) 379-384

[4] A. Artieda and P. Muralt, "High-Q AlN/SiO2 Symmetric Composite Thin Film Bulk Acoustic Wave Resonators" IEEE Transactions on Ultrasonics, Ferroelectrics, and Frequency Control, vol. 55, $\mathrm{n}^{\circ} 11$ (2008) pp. 2463-2468.
[5] Alvaro Artieda, Cosmin Sandu, and Paul Muralt Highly piezoelectric AlN thin films grown on amorphous, insulating substrates, Journal of Vacuum, Science and Tecnology A, 28 (2010) pp. 390-394.

[6] E. Iborra, J. Olivares, M. Clement, L. Vergara, A. Sanz-Hervás, J. Sangrador, "Piezoelectric properties and residual stress of sputtered AlN thin films for MEMS applications", Sensors and Actuators A 115 (2004) 501-507

[7] V.V. Felmetsger, P.N. Laptev, S.M. Tanner, "Design, operation mode, and stress control capability of S-Gun magnetron for ac reactive sputtering", Surface \& Coatings Technology 204 (2009) pp. 840-844.

[8] J. Olivares, M. Clement, S. González-Castilla, L. Vergara, E. Iborra, J. Sangrador, "Porous silicon oxide sacrificial layers deposited by pulseddirect current magnetron sputtering for microelectromechanical systems," Thin Solid Films 518 (2010) pp. 5128-5133

[9] J. Capilla, J. Olivares, M. Clement, J. Sangrador, E Iborra, A Devos, "Characterization of amorphous tantalum oxide for insulating acoustic mirrors", Proceedings of the 2011 IEEE International Frequency Control and the European Frequency and Time Forum Joint Conference, May (2011), pp 1-6.

[10] A. Brudnik, M. Bucko, M. Radecka, A. Trenezek-Zajac, K. Zakrzewska, Microstructure and optical properties of photoactive TiO2:N thin films Vacuum, 82 (2008) 936-941.

[11] Z-Y. Chen, Y. Hu, T-C. Liu, C.-L. Huang, T-S. Jeng, "Mesoporous $\mathrm{TiO} 2$ thin films embedded with Au nanoparticles for the enhancement of the photocatalytic properties," Thin Solid Films 517 (2009) pp. 4998-5000.

[12] K. Kubo, N. Tsukimura, F. Iwasa, T. Ueno, L. Saruwatari, H. Aita, WA. Chiou, T. Ogawa, "Cellular behavior on $\mathrm{TiO} 2$ nanonodular structures in a micro-to-nanoscale hierarchy model" Biomaterials 30 (2009) pp. 5319-5329.

[13] U. Diebold, "The surface science of titanium dioxide" Surface Science Reports 48 (2003) pp. 53-229

[14] H. Sun, C.Wang, S. Pang, X. Li, Y. Tao, H. Tang, M. Liu, "Photocatalytic TiO2 films prepared by chemical vapor deposition at atmosphere pressure," Journal of Non-Crystalline Solids 354 (2008) pp. 1440-1443.

[15] S.H. Woo, C.K. Hwangbo, "Influence of plasma ion-beam assistance on $\mathrm{TiO} 2$ and $\mathrm{MgF} 2$ thin films deposited by plasma ion-assisted deposition" Surface and Coatings Technology 201 (2007) pp. 82508257.

[16] D.Wang, B. Yu, J. Hao,W. Liu, Evaporizing-deposition to synthesize micro- and nanoscale spherical anatase $\mathrm{TiO} 2$ film," Materials Letters 62 (2008) pp. 2036-2038.

[17] M. Addamo, V. Augugliaro, A. Di Paola, E. Garcia-Lopez, V. Loddo, G. Marci, L. Palmisano, Photocatalytic thin films of TiO2 formed by a sol-gel process using titanium tetraisopropoxide as the precursor," Thin Solid Films 516 (2008) pp. 3802-3807.

[18] M. Horprathum, P. Eiamchai, P. Limnonthakul, N. Nuntawong, P. Chindaudom, A. Pokaipisit, P.Limsuwan Structural, optical and hydrophilic properties of nanocrystalline $\mathrm{TiO} 2$ ultra-thin films prepared by pulsed-de reactive magnetron sputtering, Journal of Alloys and Compounds 509 (2011) pp. 4520-4524.

[19] S.B. Amor, L. Guedri, G. Baud, M. Jacquet, M. Ghedira, "Influence of the temperature on the properties of sputtered titanium oxide films," Materials Chemistry and Physics 77 (2003) pp. 903-911.

[20] M. Clement, J. Olivares, E. Iborra, S. González-Castilla, N. Rimmer, A. Rastogi, "AlN films sputtered on iridium electrodes for bulk acoustic wave resonators," Thin Solid Films 517 (2009) pp. 4673-4678.

[21] C. K. Campbell, Surface Acoustic Wave Devices for Mobile and Wireless Communications, Academic, San Diego, CA 1998.

[22] E. Iborra, L. Vergara, J. Sangrador, M. Clement, A. Sanz-Hervás, J. Olivares, "Circuital Model for the Analysis of the Piezoelectric response of AlN Films Using SAW Filters," IEEE Trans. Ultrason. Ferr. Freq. Control, vol. 54 n ${ }^{\circ}$ 11, pp. 2367-2375, Dec. 2007.

[23] A. Sanz-Hervás, M. Clement, E. Iborra, L. Vergara, J. Olivares, and J. Sangrador, "Degradation of the piezoelectric response of sputtered caxis AIN thin filmswith traces of non-0002 X-ray diffraction peaks," Applied Physics Letters 88, 161915 (2006). 